\title{
Intoxicação por Cnidoscolus phyllacanthus (Euphorbiaceae) em caprinos ${ }^{1}$
}

\author{
Diego M. Oliveira², Luciano A. Pimentel², José A.S. Araújo², Rosane M.T. \\ Medeiros $^{2}$, Antonio F.M. Dantas ${ }^{2}$ e Franklin Riet-Correa ${ }^{2^{*}}$
}

\begin{abstract}
Oliveira D.M., Pimentel L.A., Araújo J.A.S., Medeiros R.M.T., Dantas A.F.M. \& Riet-Correa F. 2008. [Poisoning by Cnidoscolus phyllacanthus (Euphorbiaceae) in goats.] Intoxicação por Cnidoscolus phyllacanthus (Euphorbiaceae) em caprinos. Pesquisa Veterinária Brasileira 28(1):36-42. Hospital Veterinário, CSTR, Universidade Federal de Campina Grande, Campus de Patos, 58700-000 Patos, PB, Brazil. E-mail: franklin.riet@pq.cnpq.br

Cnidoscolus phyllacanthus (Euphorbiaceae), with the common name favela, is a generally spiny plant of the Brazilian semiarid. Mainly during the dry season livestock browse its leaves from the shrubs or ingest the dry leaves fallen to the ground. Farmers report the spontaneous poisoning by this plant when livestock has access to shrubs or branches that had been cut. Different parts of the ground fresh plant, diluted in water, are used by people in the semiarid to hunt birds. To determine the toxicity of $C$. phyllacanthus, leaves of the non-spiny plant were fed by hand to a goat by putting small amount into its mouth. After the consumption of $4.7 \mathrm{~g} / \mathrm{kg}$ body weight, the goat had tachycardia, tachypnoea, dyspnoea, nystagmus, opisthotonos and sternal recumbence. The death occurred 30 minutes after the onset of clinical signs. Fresh leaves from the same plants were given to 8 goats at doses of $0.5-2.5 \mathrm{~g} / \mathrm{kg}$ without causing clinical signs. Three goats showed clinical signs after the ingestion of $3 \mathrm{~g} / \mathrm{kg}$. Clinical signs were similar to those observed in cyanide poisoning. Two goats given $0.5 \mathrm{mg} / \mathrm{kg}$ of a $20 \%$ solution of sodium thiosulphate recovered immediately after treatment. Another goat recovered spontaneously. Leaves from the same plants were sun-dried during variable periods for 8-30 days, and then given to 8 goats. The goat that ingested the plant dried at the sun during 8 days died after the ingestion of $3 \mathrm{~g} / \mathrm{kg}$. The goat that ingested the plant, exposed to the sun for 9 days, showed clinical signs after the ingestion of $1.13 \mathrm{~g} / \mathrm{kg}$, but recovered spontaneously. The goats that ingested the leaves exposed to the sun during 10-29 days showed clinical signs after the ingestion of $3 \mathrm{~g} /$ $\mathrm{kg}$, but recovered spontaneously or after treatment with sodium thiosulphate. No clinical signs were observed in the goat that ingested the plant that had been exposed to the sun during 30 days. In another experiment ground leaves of the plant were dried at the sun for 1, 2, 3, and 4 days and given to goats at the dose of $3 \mathrm{~g} / \mathrm{kg}$. Goats that received the plant dried for 1,2 or 3 days showed clinical signs, but recovered spontaneously. The goat that ingested the plant dried 4 days showed no clinical signs. Leaves of the spineless $C$. phyllacanthus used in the experiments, 20 samples of leaves from spiny plants, 3 samples of the ground plant stem, and 2 samples of fruits were positive with the picrosodic paper test for HCN. These results demonstrated that $C$. phyllacanthus is a cyanogenic plant. After being cut the entire leaves maintain their toxicity for up to 30 days, and the ground leaves for up to 3 days. After the end of the raining season dry leaves fallen to the ground and tested within a short period were negative for HCN. These results have to be taken into account for the use of $C$. phyllacanthus as forage.

INDEX TERMS: Cnidoscolus phyllacanthus, plant poisoning, cyanide poisoning, goats, semiarid.
\end{abstract}

\footnotetext{
${ }^{1}$ Recebido em 14 de agosto de 2007.

Aceito para publicação em 3 de outubro de 2007.

${ }^{2}$ Hospital Veterinário, Centro de Saúde e Tecnologia Rural (CSTR), UFCG, Campus de Patos, 58700-000 Patos, PB, Brasil. *Autor para correspondência: franklin.riet@pq.cnpq.br
}

RESUMO.- Cnidoscolus phyllacanthus (Euphorbiaceae), com nome popular de favela, é uma planta normalmente espinhosa comum na caatinga. É considerada como forrageira e os animais, principalmente durante a seca, consomem as folhas que estão ao seu alcance ou as folhas 
secas caídas. A intoxicação espontânea por esta planta é relatada por fazendeiros no semi-árido quando animais têm acesso a plantas ou ramos recentemente cortados. Diferentes partes da planta moídas e secas, diluídas em água, são utilizadas por caçadores para matar pássaros. Para determinar a toxicidade de C. phyllacanthus, folhas verdes de plantas sem espinhos foram administradas a uma cabra em pequenas quantidades por via oral. Após o consumo de $4,7 \mathrm{~g}$ por $\mathrm{kg}$ de peso do animal $(\mathrm{g} / \mathrm{kg})$ a cabra apresentou taquicardia, taquipneia, dispnéia, nistagmo, opistótono e decúbito esterno abdominal seguido de decúbito lateral. A morte ocorreu 30 minutos após o começo dos sinais. Folhas frescas de plantas sem espinho foram administradas a 8 caprinos em doses de 0,5-2,5g/kg sem que causassem sinais clínicos. Três animais apresentaram sinais clínicos após a ingestão de $3 \mathrm{~g} / \mathrm{kg}$. Os sinais clínicos foram similares aos observados na intoxicação por ácido cianídrico e dois animais tratados com uma solução de tiossulfato de sódio a $20 \%$, na dose de $0,5 \mathrm{ml} / \mathrm{kg}$ se recuperaram rapidamente em seguida ao tratamento. O terceiro recuperou-se espontaneamente. Folhas das mesmas plantas foram secadas ao sol durante períodos varáveis de 8-30 dias. O caprino que ingeriu a planta que tinha sido secada por 8 dias morreu após a ingestão de $3 \mathrm{~g} / \mathrm{kg}$. O caprino que ingeriu a planta secada por 9 dias apresentou sinais clínicos após a ingestão de $1,13 \mathrm{~g} / \mathrm{kg}$ e se recuperou. Os caprinos que ingeriram a planta exposta ao sol por 10-29 dias apresentaram sinais clínicos após a ingestão de $3 \mathrm{~g} / \mathrm{kg}$ e se recuperaram espontaneamente ou mediante tratamento com tiossulfato de sódio. $\mathrm{O}$ caprino que ingeriu a planta que tinha sido exposta ao sol por 30 dias não apresentou sinais clínicos. Em outro experimento, 4 caprinos receberam uma dose de $3 \mathrm{~g} / \mathrm{kg}$ de folhas da planta triturada e seca ao sol por 1, 2, 3 e 4 dias. Os animais que receberam as folhas que tinham sido dessecadas por 1, 2 e 3 dias apresentaram sinais clínicos leves e se recuperaram espontaneamente. $\mathrm{O}$ caprino que ingeriu a planta exposta ao sol por 4 dias não apresentou sinais clínicos. Folhas da planta sem espinho utilizada nos experimentos, 20 amostras de folhas de plantas com espinhos, 5 amostras de raspa do caule e 2 amostras de frutos foram positivas para ao teste do papel prosódico para $\mathrm{HCN}$. Após o final da época das chuvas, folhas maduras e secas, que cairiam das árvores em um curto período foram negativas para $\mathrm{HCN}$. Esses resultados demonstraram que $C$. phyllacanthus é uma planta cianogênica que causa intoxicação após a ingestão da planta fresca. Após serem arrancadas as folhas íntegras mantêm a toxicidade por até 30 dias e as folhas moídas por até 3 dias. Com base nessa informação são recomendadas medidas de profilaxia da intoxicação para a utilização da planta como forrageira.

TERMOS DE INDEXAÇÃO: Cnidoscolus phyllacanthus, intoxicações por plantas, intoxicação por ácido cianídrico, caprinos, semi-árido.

\section{INTRODUÇÃO}

Cnidoscolus phyllacanthus (M. Arg. \& Pax et Hoffm.) conhecida por favela ou faveleira (Fig.1 e 2) é uma planta

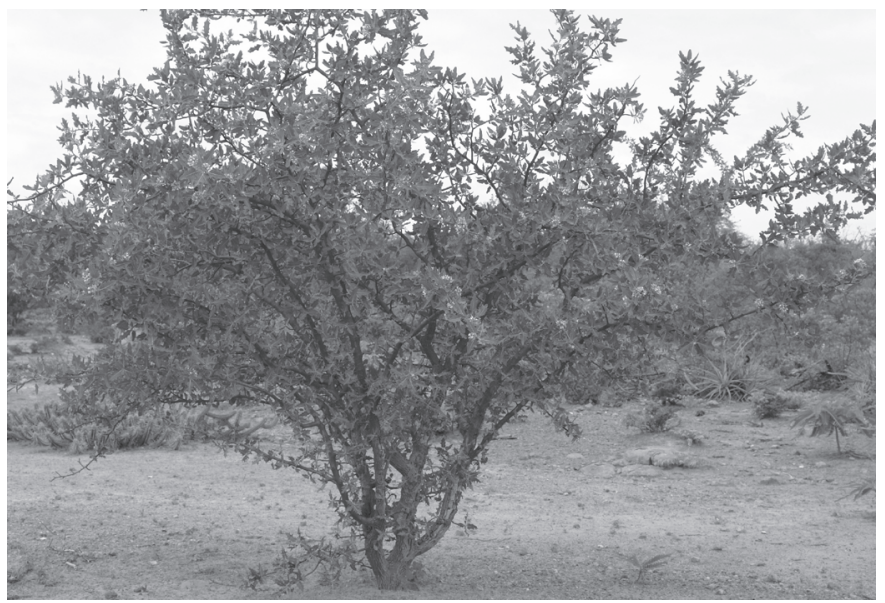

Fig.1. Cnidoscolus phyllacanthus com espinhos. Município de Patos, Paraíba.

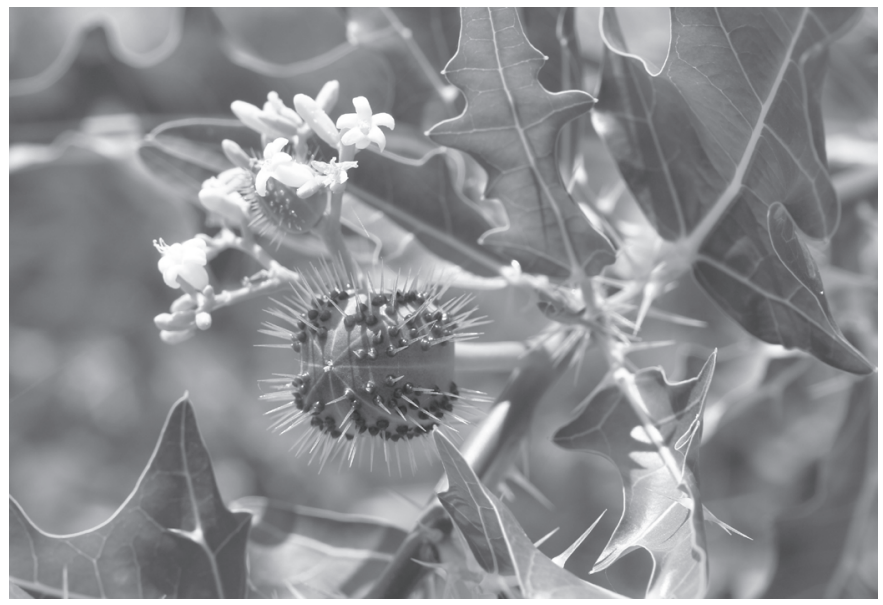

Fig.2. Folhas, frutos e flores de Cnidoscolus phyllacanthus com espinhos. Município de Patos, Paraíba.

arbórea, xerófila, lactescente, que possui pêlos urticantes. Ocorre em todo o semi-árido em regiões de caatinga que envolve áreas dos Estados do Ceará, Rio Grande do Norte, Paraíba, Pernambuco, Alagoas, Sergipe, sudoeste do Piauí, partes do interior da Bahia e do norte de Minas Gerais.

A favela é uma planta espinhenta cujas folhas e ramos novos são considerados de valor forrageiro (Lorenzi 1998) sendo que existem exemplares sem espinhos (Fig.3), que estão sendo selecionados para este fim. No período chuvoso na caatinga, que ocorre geralmente de janeiro a maio, os animais consumem as folhas verdes e os frutos. No final das chuvas as folhas amadurem e caem, sendo, também, consumidas. No período de seca a favela fica com poucas folhas e como há poucas alternativas para alimentação os animais consomem parte dos brotos e a casca (Cavalcanti e Resende. 2006). O caule novo, folhas e ramos são transformados em farelo e ministrados ao gado bovino, caprino e ovino (Oliveira Júnior et al. 2005).

O desbaste, que consiste em cortar algumas árvores e arbustos a determinada altura para aumentar a disponi- 


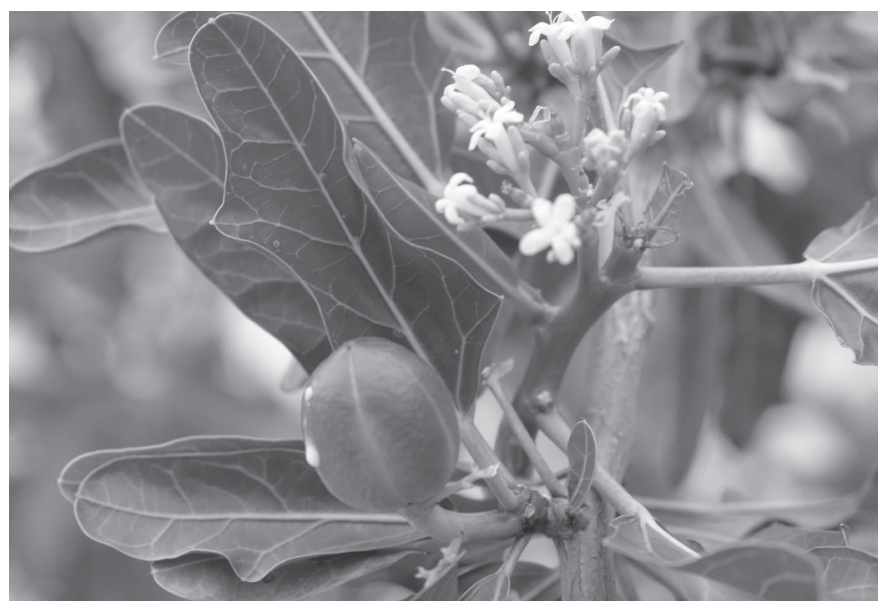

Fig.3. Folhas, frutos e flores de Cnidoscolus phyllacanthus sem espinhos. Município de Patos, Paraíba.

bilidade da forragem de árvores e arbustos, melhorar a sua qualidade bromatológica e estender a produção de folhagem verde por mais tempo na estação seca, assim como o raleamento, que consiste em eliminar algumas espécies para favorecer outras, e o desmatamento são práticas comuns na caatinga. Produtores da região semiárida dos estados da Paraíba e Rio Grande do Norte relatam casos espontâneos de intoxicação por favela em caprinos que ingerem as folhas murchas após o desbaste, raleamento ou desmatamento e mencionam que após o consumo, os animais morrem logo em seguida.

Em Caicó, Rio Grande do Norte, morreram 15 animais, na maioria adultos de um rebanho de 100 caprinos. O produtor relatou que após cortar a favela que se encontrava próximo do açude, alguns animais começaram a comer as folhas e ramas murchas; em seguida os animais caiam no chão em decúbito lateral e apresentaram movimentos de pedalagem e berros. Após observar as mortes retirou imediatamente o rebanho do local e queimou a favela. Outro caso de intoxicação foi relatado por um produtor em Patos, Paraíba, onde morreram 3 caprinos de um rebanho de 30 , com histórico e sinais clínicos semelhantes.

$\mathrm{Na}$ região semi-árida a maniçoba (Manihot spp.) (Albuquerque et al. 2004) e a favela (dados não publicados fornecidos por produtores no semi-árido da Paraíba, 2006) têm sido utilizadas para caçar aves. Devido à escassez de água no sertão as aves têm poucos lugares para beber água. Os caçadores cavam cacimbas no leito de rios ou utilizam poças dos lajedos e colocam uma solução de maniçoba ou favela (feita com a raspa do tronco) para caçar arribaçã (Zenaida auriculata) ou outras aves. Logo que as aves bebem dessa água morrem quase que imediatamente. Segundo Albuquerque et al. (2004) este ato pode envenenar também seres humanos e outros animais devido à escassez de água na região.

Este estudo teve por objetivos verificar a toxicidade de Cnidoscolus phyllacanthus para caprinos, descrever o quadro clinico-patológico e compará-lo com os relatos das intoxicações espontâneas, identificar o principio tóxico da plan- ta e determinar medidas de profilaxia da intoxicação quando a mesma for utilizada como alternativa na alimentação animal na região da caatinga.

\section{MATERIAL E METODOS}

\section{Reprodução experimental da intoxicação}

A planta foi administrada a 23 caprinos da raça Moxotó, pesando de 7,3 a $28 \mathrm{~kg}$ e com idade de 7 meses a 2 anos. Os experimentos foram realizados no Hospital Veterinário $(\mathrm{HV})$ do CSTR/UFCG, Campus de Patos, PB, no período de julho de 2006 a julho de 2007.

Foram utilizadas folhas de favela sem espinho (Fig.3) coletadas no próprio HV, e administradas manualmente por via oral, em dose única, colocando pequenas quantidades na boca até que $\mathrm{o}$ animal as deglutisse totalmente. Os Caprinos 2 e 7 consumiram a planta voluntariamente.

Para a determinação da quantidade de planta a ser administrada, os animais eram deixados em jejum de 24 horas e pesados no final desse período. Antes e após a administração foram verificadas as freqüências cardíaca e respiratória, os movimentos ruminais e a temperatura corporal. A administração teve duração que variou de 1 a 25 minutos para cada animal. Durante e após a administração era acompanhado o estado clínico do animal. Se o caprino apresentava sinais antes do fim da administração a mesma era suspensa. Os sinais clínicos foram classificados em leves naqueles animais que não apresentaram decúbito, moderados quando os caprinos apresentaram decúbito esterno-abdominal e acentuados nos caprinos que entraram em decúbito lateral.

Após a morte de 2 animais foi suspeitado que $C$. phyllacanthus causava intoxicação por HCN. Para comprovar esse fato, foi realizado o teste do papel picrosódico nas folhas sem espinho recém colhidas e nas folhas trituradas e secadas ao sol. A intensidade da reação do papel picrosódico foi classificada em reação acentuada (quando o tempo de mudança de coloração para vermelho era de até 5 minutos), moderada (quando o tempo de mudança da coloração era de 5 a 10 minutos), leve (quando o tempo de mudança de coloração passava dos 10 minutos até 3 horas) e discreta (quando mudava de coloração para o vermelho após 3 horas ou quando apenas mudava de coloração para o laranja).

Os Caprinos 8 e 9, que apresentaram decúbito esternoabdominal e os Caprinos 13, 14 e 15, que apresentaram decúbito lateral, foram tratados com uma solução aquosa de tiossulfato de $\mathrm{Na}$ a $20 \%$ na dosagem de $0,5 \mathrm{ml} / \mathrm{kg}$ por via endovenosa, na veia jugular. Nos Caprinos 1 e 10, que morreram, foram realizadas necropsias para verificar alterações macroscópicas. Amostras do aparelho digestivo, fígado, baço, pulmão, rim, coração e sistema nervoso central foram fixados em formol a $10 \%$, incluídas em parafina, cortadas em seções de $6 \mu \mathrm{m}$ e coradas por hematoxilina e eosina para exame histopatológico.

$\mathrm{O}$ trabalho foi dividido em 4 experimentos. No Experimento 1 foram utilizados 9 caprinos aos quais foram administradas folhas recém colhidas (frescas). No Experimento 2 foram coletados galhos de até $1 \mathrm{~cm}$ de diâmetro e deixados expostos ao sol, no campo, para secar por 8, 9, 10, 15, 20, 25, 29 e 30 dias. Após esse período as folhas, que estavam totalmente secas, foram retiradas dos galhos e administradas a 8 caprinos. No Experimento 3, folhas de favela foram coletadas e trituradas na forrageira (com peneira grossa) e posteriormente deixadas sobre uma caixa de papelão para serem secadas ao sol. A 
Quadro 1. Reprodução experimental da intoxicação por Cnidoscolus phyllacanthus. Material utilizado, dose administrada, tempo de administração, sinais clínicos e evolução

\begin{tabular}{|c|c|c|c|c|c|c|c|c|}
\hline \multirow{3}{*}{$\begin{array}{c}\text { Caprino } \\
n^{\circ} \times\end{array}$} & \multicolumn{2}{|c|}{ Folha da Planta } & \multirow{3}{*}{$\begin{array}{l}\text { Dose } \\
(\mathrm{g} / \mathrm{kg})\end{array}$} & \multirow{2}{*}{\multicolumn{4}{|c|}{$\begin{array}{l}\text { Tempo de Administração e sinais clínicos } \\
\text { adminis- } \quad \text { (min após administração) }\end{array}$}} & \multirow[t]{3}{*}{ Evolução } \\
\hline & \multirow[t]{2}{*}{ Tipo } & \multirow{2}{*}{$\begin{array}{l}\text { Dias de } \\
\text { secagem }\end{array}$} & & & & & & \\
\hline & & & & $\begin{array}{c}\text { tração } \\
\text { (min) }\end{array}$ & Início & Duraçã & Intensidade & \\
\hline 01 & fresca & - & 4,7 & 15 & $D^{a}$ & 30 & Acentuada & Morreu \\
\hline 02 & fresca & - & 0,5 & 01 & - & $\mathrm{SS}^{\mathrm{b}}$ & - & - \\
\hline 03 & fresca & - & 1,0 & 05 & - & SS & - & - \\
\hline 04 & fresca & - & 1,5 & 05 & - & SS & - & - \\
\hline 05 & fresca & - & 2,0 & 14 & - & SS & - & - \\
\hline 06 & fresca & - & 2,5 & 13 & - & SS & - & - \\
\hline 07 & fresca & - & 3,0 & 02 & $\mathrm{IAA}^{\mathrm{C}}$ & 180 & Moderada & Recuperação espontânea \\
\hline 08 & fresca & - & 3,0 & 14 & IAA & 31 & Moderada & Tratado d \\
\hline 09 & fresca & - & 3,0 & 10 & IAA & 27 & Moderada & Tratado \\
\hline 10 & Seca & 8 & 3,0 & 25 & 2 & 48 & Acentuada & Morreu \\
\hline 11 & Seca & 9 & 1,1 & 23 & DA & 240 & Leve & Recuperação espontânea \\
\hline 12 & seca & 10 & 3,0 & 12 & 1 & 120 & Leve & Recuperação espontânea \\
\hline 13 & Seca & 15 & 3,0 & 18 & 4 & 31 & Acentuada & Tratado \\
\hline 14 & Seca & 20 & 3,0 & 14 & 3 & 7 & Acentuada & Tratado \\
\hline 15 & Seca & 25 & 3,0 & 7 & 5 & 16 & Acentuada & Tratado \\
\hline 16 & Seca & 29 & 3,0 & 8 & 10 & 30 & Leve & Recuperação espontânea \\
\hline 17 & seca & 30 & 3,0 & 12 & - & - & - & - \\
\hline 18 & Seca triturada & a 1 & 3,0 & 16 & 4 & 105 & Leve & Recuperação espontânea \\
\hline 19 & Seca triturada & a 2 & 3,0 & 20 & 5 & 115 & Leve & Recuperação espontânea \\
\hline 20 & Seca triturada & a 3 & 3,0 & 15 & 4 & 96 & Leve & Recuperação espontânea \\
\hline 21 & Seca triturada & a 4 & 3,0 & 07 & - & SS & - & Recuperação espontânea \\
\hline 22 & Madura ${ }^{\mathrm{e}}$ & - & 3,0 & 12 & - & SS & - & - \\
\hline 23 & Madura & - & 3,0 & 9 & - & SS & - & - \\
\hline
\end{tabular}

a DA = Apresentou sinais antes do final da administração; ${ }^{b}$ IAA = Apresentou sinais clínicos imediatamente após a administração; ${ }^{\mathrm{c}} \mathrm{SS}=\mathrm{Sem}$ sinais clínicos; ${ }^{\mathrm{d}}$ Recuperado após o tratamento; ${ }^{\mathrm{e}}$ Folhas secas (amarelas) próximas a cair das árvores.

camada de folhas tinha no máximo $1 \mathrm{~cm}$ de altura e era revirada 4 vezes por dia. As folhas moídas e secas foram administradas a 4 caprinos. O Experimento 4 foi realizado após o final do período de chuvas, com a folha da favela madura, amarela, que estava próxima a cair. As folhas foram coletadas diretamente da planta e logo em seguida administradas a 2 caprinos na dose de $3 \mathrm{~g} / \mathrm{kg}$. A planta utilizada, a dose administrada e o tempo de administração em cada caprino experimental constam no Quadro 1.

Para o grupo controle foram utilizados 16 caprinos, semelhantes aos dos grupos experimentais, nos quais se verificavam as freqüências cardíaca e respiratória, os movimentos ruminais e a temperatura corporal, antes e após a administração da planta aos caprinos experimentais. Por cada caprino experimental era utilizado um controle.

Para verificar o teor de matéria seca da folha da favela sem espinho foram coletadas 100 gramas de folhas e secadas até que o peso final não apresentasse variações.

\section{Determinação de glicosídeos cianogênicos em Cnidoscolus phyllacanthus com espinhos}

Para determinar a presença de glicosídeos cianogênicos em $C$. phyllacanthus com espinhos foi utilizado o teste do papel picrosódico descrito anteriormente, utilizado vinte amostras de folhas verdes frescas com espinho, 5 amostras da raspa da casca da planta e 2 de frutos verdes, de diferentes plantas de C. phyllacanthus coletadas nos municípios de Patos e São José do Bonfim, Paraíba. Também foi realizado o teste em 2 amostras de folhas maduras, amarelas, que estavam próximas a cair, coletadas após o final do período de chuvas.

\section{RESULTADOS}

Reprodução experimental da intoxicação por Cnidoscolus phyllacanthus

Intoxicação com a planta fresca (Exp. 1). O Caprino 1 que teria que receber $10 \mathrm{~g} / \mathrm{kg}$, começou a apresentar sinais clínicos após ter recebido $4,73 \mathrm{~g} / \mathrm{kg}$ da planta verde após 15 minutos de administração. Os sinais clínicos caracterizaram-se por taquicardia, taquipnéia com dispnéia, berros constantes, pulso venoso positivo, timpanismo, movimentos involuntários da cabeça, ataxia, instabilidade dos membros, decúbito esterno-abdominal e em seguida decúbito lateral com movimentos de pedalagem, opistótono, nistagmo horizontal, midríase, mioclonia e tetania. Morreu 30 minutos após o início dos sinais clínicos. Os Caprinos 2, 3, 4, 5 e 6 que receberam de 0,5 a 2,5 $\mathrm{g} / \mathrm{kg}$ não apresentaram sinais de intoxicação. Os Caprinos 7 , 8 e 9, que consumiram $3 \mathrm{~g} / \mathrm{kg}$ apresentaram sinais clínicos logo após o término da administração. O Caprino 7 apresentou sinais clínicos menos severos que o anterior apresentando taquicardia, taquipneia acompanhado de dispnéia, instabilidade dos membros, tremores musculares leves, berros constantes, relutância em caminhar, decúbito esterno-abdominal, pulso venoso positivo, midriase, nistagmo horizontal, diminuição do tonus muscular da mandíbula e língua fácil de ser tracionada, poliúria, pelo arrepiado, cabeça voltada para o flanco direito e apatia. Após 3 horas do início dos sinais clínicos encontrava- 
se com uma leve apatia e no dia seguinte se encontrava totalmente recuperado. Os Caprinos 8 e 9 apresentaram sinais clínicos semelhantes aos observados no animal anterior. Após apresentarem decúbito esterno-abdominal, foram tratados com tiossulfato de sódio e se recuperaram logo em seguida.

Intoxicação com a planta seca (Exp. 2). O Caprino 10 , que recebeu $3 \mathrm{~g} / \mathrm{kg}$ de folhas que tinham sido dessecadas por 8 dias, morreu 48 minutos depois de observados os primeiros sinais clínicos. Os sinais clínicos foram semelhantes aos observados no Caprino 1. O Caprino 11 , que recebeu folhas que tinham sido secadas por 9 dias, apresentou, após ter ingerido $1,13 \mathrm{~g} / \mathrm{kg}$, taquipneia com dispnéia, taquicardia, pulso venoso positivo, atonia ruminal, apatia e anorexia. Recuperou-se espontaneamente não apresentando nenhum sinal no dia seguinte à administração. O Caprino 12, que recebeu folhas dessecadas por 10 dias na dose de $3,0 \mathrm{~g} / \mathrm{kg}$, apresentou taquicardia, taquipnéia e apatia e se recuperou espontaneamente 2 horas após o início dos sinais clínicos. Os Caprinos 13, 14 e 15 que receberam as folhas que tinham sido expostas ao sol por 15 , 20 e 25 dias, respectivamente, apresentaram sinais clínicos semelhantes ao Caprino 1, e foram tratados com tiossulfato de $\mathrm{Na}$ a $20 \%$ após entrar em decúbito lateral. $\mathrm{O}$ Caprino 16 que recebeu folhas expostas ao sol por 29 dias, apresentou sinais de intoxicação leve e se recuperou espontaneamente. O Caprino 17 que ingeriu as folhas dessecadas por 30 dias não apresentou sinais de intoxicação. Os 7 animais utilizados no experimento com exceção do Caprino 17 apresentaram sinais clínicos logo após o término da administração.

Intoxicação com a planta triturada e seca ao sol (Exp. 3). Todos os caprinos desse experimento receberam uma dosagem de $3 \mathrm{~g} / \mathrm{kg}$. Os Caprinos 18, 19, 20 e 21 receberam folhas trituradas e dessecadas por um período de 1, 2, 3 e 4 dias ao sol, respectivamente. Os Caprinos 18, 19 e 20 apresentaram taquicardia e taquipneia, sendo que os de

Quadro 2. Reações ao teste do papel picrosódico das folhas (frescas ou dessecadas ao sol, trituradas ou não), raspa do caule e frutos de Cnidoscolus phyllacanthus sem espinho das plantas utilizadas para a reprodução experimental

\begin{tabular}{ccccc}
\hline $\begin{array}{c}\text { Amostra } \\
\mathrm{n}^{\underline{0}}\end{array}$ & $\begin{array}{c}\text { Material utilizado } \\
\text { (dias exposto ao sol) }\end{array}$ & $\begin{array}{c}\text { Tempo (minutos) para } \\
\text { apresentar a reação }\end{array}$ & Intensidade \\
\cline { 3 - 4 } & & 2 & 4 & Acentuada \\
01 & Foranja & Vermelho & \\
02 & Folha & 1 & 4 & Acentuada \\
03 & Folha triturada & 1 & 3 & Acentuada \\
04 & Folha triturada (1) & 20 & 180 & Leve \\
05 & Folha triturada (2) & 60 & 240 & Discreta \\
06 & Folha triturada (3) & 180 & 600 & Discreta \\
07 & Folha triturada (4) & 600 & - & Discreta \\
08 & Raspa do caule & 6 & 18 & Leve \\
09 & Raspa do caule & 5 & 9 & Moderada \\
10 & Fruto & 6 & 35 & Leve \\
11 & Fruto & 7 & 19 & Leve \\
12 & Folha madura & 4 & 7 & Leve \\
13 & Folha madura & 4 & 6 & Leve
\end{tabular}

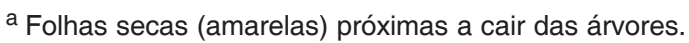

Quadro 3. Reações ao teste do papel picrosódico das folhas frescas e maduras, raspa do caule e frutos de Cnidoscolus phyllacanthus com espinho, logo após a sua colheita

\begin{tabular}{|c|c|c|c|c|}
\hline \multirow[t]{2}{*}{$\begin{array}{c}\text { Amostra } \\
n^{\circ}\end{array}$} & \multirow[t]{2}{*}{ Material utilizado } & \multicolumn{2}{|c|}{$\begin{array}{l}\text { Tempo (minutos) para } \\
\text { apresentar a reação }\end{array}$} & \multirow[t]{2}{*}{ Intensidade } \\
\hline & & Laranja & Vermelho & \\
\hline 1 & Folhas & 2 & 5 & Acentuada \\
\hline 2 & Folhas & 2 & 4 & Acentuada \\
\hline 3 & Folhas & 2 & 5 & Acentuada \\
\hline 4 & Folhas & 1 & 3 & Acentuada \\
\hline 5 & Folhas & 2 & 5 & Acentuada \\
\hline 6 & Folhas & 1 & 3 & Acentuada \\
\hline 7 & Folhas & 1 & 3 & Acentuada \\
\hline 8 & Folhas & 1 & 3 & Acentuada \\
\hline 9 & Folhas & 1 & 3 & Acentuada \\
\hline 10 & Folhas & 1 & 3 & Acentuada \\
\hline 11 & Folhas & 1 & 2 & Acentuada \\
\hline 12 & Folhas & 1 & 2 & Acentuada \\
\hline 13 & Folhas & 1 & 3 & Acentuada \\
\hline 14 & Folhas & 2 & 4 & Acentuada \\
\hline 15 & Folhas & 1 & 3 & Acentuada \\
\hline 16 & Folhas & 1 & 3 & Acentuada \\
\hline 17 & Folhas & 2 & 4 & Acentuada \\
\hline 18 & Folhas & 1 & 2 & Acentuada \\
\hline 19 & Folhas & 1 & 3 & Acentuada \\
\hline 20 & Folhas & 1 & 2 & Acentuada \\
\hline 21 & Raspa do caule & 1 & 3 & Acentuada \\
\hline 22 & Raspa do caule & 4 & 10 & Moderada \\
\hline 23 & Raspa do caule & 3 & 8 & Moderada \\
\hline 24 & Raspa do caule & 5 & 9 & Moderada \\
\hline 25 & Raspa do caule & 6 & 11 & Leve \\
\hline 26 & Frutos & 5 & 13 & Leve \\
\hline 27 & Frutos & 11 & 22 & Leve \\
\hline 28 & Folhas maduras ${ }^{a}$ & 4 & 6 & Leve \\
\hline 29 & Folhas maduras & 4 & 7 & Leve \\
\hline
\end{tabular}

a Folhas secas (amarelas) próximas a cair das árvores.

número 18 e 19 também apresentaram tremores musculares leves e uma diminuição discreta dos movimentos ruminais. O Caprino 19 apresentou, também, relutância em se movimentar e pulso venoso positivo. Os Caprinos 18, 19 e 20 se recuperaram espontaneamente após 105, 115 e 96 minutos, respectivamente. O Caprino 21, que recebeu folhas moídas e dessecadas por um período de 4 dias, não apresentou sinais de intoxicação.

Administração de folhas maduras (amarelas) antes de caírem das árvores (Exp. 4). Os Caprinos $22 \mathrm{e}$ 23 , que receberam $3 \mathrm{~g} / \mathrm{kg}$, não apresentaram sinais de intoxicação.

Os resultados dos 4 experimentos estão resumidos no Quadro 1.

Na necropsia do Caprino 1 foi observado edema pulmonar. O Caprino 10 apresentava áreas de enfisema nos lobos apicais e edema pulmonar. Nos dois caprinos havia folhas da favela no rúmen. Na histopatologia não foram observadas lesões de significação.

O teste do papel picrosódico nas plantas utilizadas no experimento revelou ácido cianídrico, nas folhas frescas, trituradas (dessecadas ao sol) e maduras, raspa do caule e frutos sem espinho. O tempo e o grau de reação de cada uma das amostras apresentam-se no Quadro 2. 
O teste do papel picrosódico também revelou ácido cianídrico, nas folhas frescas e maduras, raspa do caule e frutos de $C$. phyllacanthus com espinho que foram submetidos ao mesmo método citado anteriormente. Quanto às folhas frescas a reação foi considerada acentuada para todas as amostras, na raspa do caule houve uma variação de acentuado a leve e nos frutos verdes a reação foi leve. Folhas que já estavam maduras nas árvores, antes de cair espontaneamente, apresentaram uma reação leve para o teste do papel picrosódico. Os resultados estão descritos no Quadro 3. Tanto nos testes de toxicidade em caprinos, quanto nos testes do papel picrosódico nas foIhas frescas e verdes da planta, não foram encontradas diferenças de toxicidade nem na presença de $\mathrm{HCN}$ em plantas coletadas em diferentes épocas do ano.

O conteúdo de matéria seca das folhas de favela sem espinhos foi de $22 \%$.

\section{Determinação de glicosídeos cianogênicos em Cni- doscolus phyllacanthus com espinhos}

Os resultados do teste do papel picrosódico em 20 amostras de folhas de diferentes plantas de C. phyllacanthus, 5 amostras de raspa do caule, 2 amostras de frutos e 2 amostras de folhas secas, mas que ainda não tinham caído das árvores são apresentados no Quadro 3.

\section{DISCUSSÃO E CONCLUSÕES}

Os resultados deste trabalho comprovam a toxicidade de Cnidoscolus phyllacanthus e demonstram que a intoxicação é causada pela presença de compostos contendo $\mathrm{HCN}$ na planta.

Pelos históricos mencionados na introdução, a planta, em condições naturais, somente causa intoxicação quando os animais ingerem folhas de galhos ou árvores que foram cortados e ficaram ao alcance dos animais. Apesar de ser uma planta palatável não há relatos de intoxicação pelo consumo da planta diretamente das árvores. Isto provavelmente por que nessas condições os animais não têm possibilidade de ingerir grandes quantidades em um curto espaço de tempo; condição indispensável para que ocorram intoxicações por plantas que contem glicosídeos cianogênicos. Geralmente, no campo, as folhas da planta são ingeridas espontaneamente em pouca quantidade quando ainda estão nas árvores ou após caírem das árvores, quando estão já secas e misturadas com outras folhas que formam o restolho, condições nas que não ocorre à intoxicação. Para a utilização de $C$. phyllacathus como forrageira devem ser considerados os seguintes critérios: 1) as folhas que caem ao solo após o final da estação chuvosa não são tóxicas; 2) deve-se evitar o acesso de animais a galhos ou plantas recém-cortadas até pelo menos 30 dias após o corte, principalmente em locais onde foi realizado desmatamento, desbaste ou raleamento; 3) se a planta está sendo administrada após o corte é aconselhável que as folhas sejam moídas e secadas ao sol por, pelo menos 3 dias; o ideal para a utilização da planta como forrageira é fazer feno para ser utilizado no período da seca. Neste caso, o feno com as folhas inteiras da planta terá perdido sua toxicidade 30 dias após o corte das mesmas. Finalmente, em propriedades do semi-árido, onde haja presença de grandes quantidades de $C$. phyllacanthus ou outras plantas cianogênicas é aconselhável que o produtor tenha solução de tiossulfato de $\mathrm{Na}$ a $20 \%$ pronta em sua propriedade, para ser aplicada aos animais intoxicados por via endovenosa na dosagem de $0,5 \mathrm{ml} / \mathrm{kg}$.

Em relação à toxicidade observa-se que a planta tem toxicidade similar ou é mais tóxica que a maioria das plantas cianogênicas da região nordeste, pois causou intoxicação com doses de $3 \mathrm{~g}$ de folhas frescas por $\mathrm{kg}$. Em trabalhos com outras plantas foi encontrada toxicidade de 6$10 \mathrm{~g} / \mathrm{kg}$ para Manihot glaziovii (Tokarnia et al. 1994a, 1999, Amorim et al. 2005), doses superiores a $2,5 \mathrm{~g} / \mathrm{kg}$ para $M$. piauhyensis (Tokarnia et al. 1994a), de 10-14,1 $/ \mathrm{kg}$ para Piptadenia viridiflora (Tokarnia et al. 1999), de $6-10 \mathrm{~g} / \mathrm{kg}$ para Anadenanthera colubrina var. cebil (=Anadenanthera (Piptadenia) macrocarpa) (Tokarnia et al. 1994b, 1999, Amorim et al. 2004) e 11,8g/kg para Sorghum halepense (Nóbrega et al. 2006). Prunus sellowii, que não ocorre no Nordeste, é tóxico nas doses de 2,5-5g/kg (Gava et al. 1992). Por outro lado, C. phyllacanthus reagiu em 1-2 minutos na prova do papel picrosódico. Outras plantas como A. macrocarpa e $P$. viridiflora, que mantêm sua toxicidade após secagem por 6 e 14 meses, respectivamente (Brito et al. 2000), reagem mais lentamente ao teste do papel picrosódico, levando entre 10 e 30 minutos. $M$. glaziovii, semelhante ao que ocorre $\operatorname{com} C$. phyllacanthus, reage em menos de 5 minutos e mantêm sua toxicidade por até 30 dias quando secada na sombra (Amorim et al. 2005). Estas diferenças são devidas, provavelmente, a presença de diferentes glicosídeos cianogênicos.

A presença de $\mathrm{HCN}$ na raspa do talo de C. phyllacanthus sugere que a morte de pássaros que bebem água contendo esta parte da planta é causada, também, pela presença de HCN na planta. Não encontramos referencias sobre a intoxicação por $\mathrm{HCN}$ em aves. Mas parece evidente que o processo de raspar o talo da planta libera enzimas que hidrolisam os glicosídeos cianogênicos liberando o HCN. Sabe-se que quando o material vegetal é dilacerado como, por exemplo, mediante a mastigação, o glicosídeo em presença de água é hidrolisado enzimaticamente por ß-glicosidases, que se encontram separados do glicosídeos no tecido vegetal intacto (Tokarnia et al. 2000, Radostits et al. 2002).

O diagnóstico presuntivo da intoxicação por $C$. phyllacanthus deve ser realizado pela presença da planta, sinais clínicos, se forem observados, e a presença de folhas da planta no rúmen. O resultado positivo ao teste do papel picrosódico e a resposta ao tratamento confirmam o diagnóstico. No diagnóstico diferencial deve incluir a intoxicação por outras plantas cianogênicas, a intoxicação por Mascagnia rigida que ocorre na mesma re- 
gião e causa morte súbita associada ao exercício (Tokarnia et al. 2000) e a intoxicação por nitratos e nitritos que, também ocorre no semi-árido (Medeiros et al. 2003).

Agradecimentos.- Este projeto foi financiado pelo programa Institutos do Milênio (Proc. 420012/2005-2).

\section{REFERÊNCIAS}

Albuquerque H.N., Albuquerque I.C.S., Menezes I.R., Monteiro J.A., Barbosa A.R. \& Cavalcanti M.L.F. 2004. Utilização da maniçoba (Manihot glaziovii, Euphorbiaceae) na caça de aves em Sertânia, PE. Revista de Biologia e Ciências da Terra 4(2):http://www.uepb.edu.br/ eduep/rbct/sumarios/pdf/manicoba2.pdf. Acessado em 26 de julho de 2007.

Amorim S.L., Medeiros R.M.T., Riet-Correa F. \& Oliveira A.C.P. 2004. Intoxicação experimental com plantas cianogênicas em bovinos. Pesq. Vet. Bras. 24(Supl.):5-6.

Amorim S.L., Medeiros R.M.T., Riet-Correa F. \& Oliveira A.C.P. 2005. Intoxicação experimental por Manihot glaziovii (Euphorbiaceae) em caprinos. Pesq. Vet. Bras. 25(3):179-187.

Brito M.F., França T.N., Oliveira K.D. \& Cerqueira V.D. 2000. Estudos experimentais em coelhos com plantas cianogênicas. Pesq. Vet. Bras. 20(2):65-70.

Cavalcanti N.B. \& Resende G.M. 2006. O consumo da favela (Cnidoscolus phyllacanthus) pelos caprinos na caatinga. O Imbuzeiro e Caatinga. Embrapa Semi-Árido, Petrolina, PE. http:// imbuzeiro.blogspot.com/search?q=favela. Acessado em 28 de janeiro de 2007.

Gava A., Stolf L., Neves D.S., Stolf O., Varaschim M.S. \& Ferreira F.M.M.
1992. Intoxicação experimental por Prunus sellowii (Rosaceae) em bovinos. Pesq. Vet. Bras. 12(1/2):1-4

Oliveira Júnior S.O., Cunha M.G.G. \& Souza W.H. 2005. Forrageiras nativas e exóticas utilizadas na produção de fenos para alimentação animal. Caprinos e ovinos, produção e processamento. Emepa, João Pessoa, PB, p.73-85

Lorenzi H. 1998. Ávores Brasileiras. Vol.2. Segunda edição. Editora Plantarum, Nova Odessa, SP, p.92

Medeiros R.M.T., Riet-Correa F., Tabosa I.M., Silva Z.A., Barbosa R.C., Marques A.V.M.S. \& Nogueira F.R.B. 2003. Intoxicação por nitratos e nitritos em bovinos por ingestão de Ehinochloa polystachya (capim-mandante) e Pennisetum purpureum (capim-elefante) no sertão da Paraíba. Pesq. Vet. Bras. 23(1):17-20.

Nóbrega Jr J.N., Riet-Correa F., Medeiros R.M.T. \& Dantas A.F.M. 2006. Intoxicação por Sorhgum halepense (Poaceae) em bovinos no semiárido. Pesq. Vet. Bras. 26(4):201-204

Radostits O.M., Gay C.C., Blood D.C. \& Hinchccliff K.W. 2002. Clínica Veterinária. 9ae ed. Guanabara Koogan, Rio de Janeiro, p.1473-1477.

Tokarnia C.H., Döbereiner J. \& Peixoto P.V. 1994a. Aspectos clínico patológicos complementares da intoxicação por algumas plantas tóxicas brasileiras. Pesq. Vet. Bras. 14(4):111-122.

Tokarnia C.H., Peixoto P.V. \& Döbereiner J. 1994b. Intoxicação experimental por Piptadenia macrocarpa (Leg. Mimosoideae) em bovinos. Pesq. Vet. Bras. 12(2/3):57-63

Tokarnia C.H., Peixoto P.V., Brito M.F., Duarte M.D. \& Brust L.A.C. 1999. Estudos experimentais com plantas cianogênicas em bovinos. Pesq. Vet. Bras. 19(2):84-90.

Tokarnia C.H., Döbereiner J. \& Peixoto P.V. 2000. Plantas Tóxicas do Brasil. Editora Helianthus, Rio de Janeiro, p.217-221. 